\title{
Management of acute respiratory distress syn- drome using pumpless extracorporeal lung assist
}

\author{
[Traitement du syndrome de détresse respiratoire aiguë avec assistance respiratoire
} extracorporelle sans pompe]

Urban Ruettimann md, ${ }^{*}$ Wolfgang Ummenhofer md, ${ }^{*}$ Florian Rueter md $†$ Hans Pargger md ${ }^{*}$

Purpose: To describe the use of a pumpless extracorporeal lung assist device in the treatment of severe acute respiratory distress syndrome (ARDS).

Clinical features: A I5-yr-old girl developed severe post-traumatic ARDS. After all conventional treatment strategies failed, we inserted a pumpless extracorporeal lung assist device. This device consists of an arterial cannula inserted into the femoral artery, and a membrane oxygenator with a venous cannula that returns the oxygenated blood back to the patient's femoral vein. Since the driving force is the patient's blood pressure, a roller pump with its negative side effects is not needed. The device allowed removal of excessive $\mathrm{PaCO}_{2}$ and, by applying minimal ventilation, minimization of further ventilator-induced lung injury. The pumpless extracorporeal lung assist device remained in situ for ten days without any adverse side effect. During this time, the lung recovered such that mechanical ventilation could be reinstalled cautiously. The device was then removed and, after a prolonged period of intensive care, the patient recovered without any sequelae.

Conclusion: In this case of a severely damaged lung, an arteriovenous pumpless extracorporeal lung assist was a helpful device to remove elevated $\mathrm{CO}_{2}$ and reduce mechanical stress by applying minimal ventilation. This device is simple to operate and has the potential of being used routinely in the treatment of severe ARDS.

Objectif : Décrire l'usage d'un appareil d'assistance respiratoire extracorporelle sans pompe dans le traitement d'un syndrome de détresse respiratoire aiguë (SDRA) sévère.

Éléments cliniques: Un SDRA post-traumatique sévère s'est développé chez une jeune fille de 15 ans. Après l'échec de toutes les stratégies habituelles de traitement, nous avons inséré un appareil d'assistance respiratoire extracorporelle sans pompe. Cet appareil comprend une canule artérielle insérée dans l'artère fémorale et un oxygénateur à membrane avec une canule veineuse qui retourne le sang oxygéné dans la veine fémorale du patient. Comme la force d'entraînement est la tension artérielle du patient, une pompe à rouleaux, qui présente des effets secondaires négatifs, n'est pas nécessaire. L'appareil permet le retrait de la $\mathrm{PaCO}_{2}$ excessive et, en appliquant une ventilation minimale, la réduction d'une lésion respiratoire supplémentaire induite par la ventilation mécanique. L'appareil est demeuré in situ pendant dix jours sans aucun effet secondaire indésirable. Pendant cette période, le poumon s'est rétabli de sorte que la ventilation mécanique a pu être réinstallée prudemment. L'appareil $a$ ensuite été retiré et, après une période prolongée de soins intensifs, la récupération de la patiente a été sans séquelles.

Conclusion : Dans ce cas d'atteinte respiratoire sévère, une assistance respiratoire artérioveineuse extracorporelle sans pompe a été très utile pour éliminer le $\mathrm{CO}_{2}$ élevé et réduire le stress mécanique en appliquant une ventilation minimale. Cet appareil est d'usage simple et peut être utilisé de routine dans le traitement du SDRA sévère.

From the Division of Operative Critical Care, Department of Anesthesia; ${ }^{*}$ and the Division of Cardiothoracic Surgery, $\dagger$ University Hospital Basel, Basel, Switzerland.

Address correspondence to: Dr. Wolfgang Ummenhofer, University Hospital Basel, Spitalstrasse 21, CH-4031 Basel, Switzerland.

Phone: +41 6126525 25; Fax: +41 6126573 20; E-mail: wummenhofer@uhbs.ch

Accepted for publication May 21, 2005.

Revision accepted August 25, 2005. 
a clear improvement in outcome. Extracorporeal membrane oxygenation (ECMO) is a controversial treatment for ARDS. Extracorporeal membrane oxygenation is used as a last effort in very severe cases, and its application is limited to specialized medical centres. ${ }^{8}$ Risks and complications of ECMO are numerous: bleeding, infections, hemolysis, thrombosis of the system, and plasma leakage are observed most frequently. Recently, a pumpless arteriovenous gas exchange device was developed (NovaLung ${ }^{\mathrm{TM}}$, $\mathrm{GmbH}$, Hechingen, Germany) that uses a membrane with a very low flow resistance. ${ }^{9}$ It allows complete removal of arterial $\mathrm{CO}_{2}$ and significant oxygenation of the arterial blood. We report its successful use in the treatment of ARDS in a 15-yr-old girl. Consent for publication was obtained from the patient's mother in accordance with our Institutional guidelines.

\section{Case report}

While hiking, a previously healthy 15 -yr-old girl fell 15 meters down a rock face. Because of respiratory distress and a Glasgow coma score of 10, her trachea was intubated at the scene. In the emergency room, a chest $x$-ray revealed small bilateral pneumothoraces, a white lung on the right side, and lung contusions on the left. Further diagnostic evaluation revealed small brain contusions and a fracture of the right lower leg. Hemodynamic parameters were stable, ultrasonography of the abdomen was normal, and her skull and spine were not injured. Accordingly, one chest drain on the left side and two on the right side were inserted. The small endotracheal tube was replaced by an early tracheotomy and, finally, the fractured tibia was stabilized by external fixation.

A few days after her arrival in the intensive care unit, a multiple organ dysfunction syndrome occurred with renal failure, ARDS, and hemodynamic instability. Two weeks after recovery from multiple organ dysfunction syndrome, a bacterial pneumonia evolved, and a second, and more severe case of ARDS developed. It was necessary to reinsert pleural drainage on both sides due to ventilator-induced pneumothoraces. Despite pressure-controlled ventilation, high respiratory rate and low-tidal volumes, prone positioning, inhaled bronchodilators, and inhaled nitric oxide, the blood gases and lung compliance continuously deteriorated. Application of higher levels of positive endexpiratory pressure failed due to a dramatic increase of air leakage through the pleural drainages. During this time, the patient was sedated to a sedation agitation score of 1 with high doses of midazolam (300 $\left.\mu \mathrm{g} \cdot \mathrm{min}^{-1} i v\right)$ and morphine $\left(100 \mu \mathrm{g} \cdot \mathrm{min}^{-1} i v\right)$. No muscle relaxants were administered. When arterial

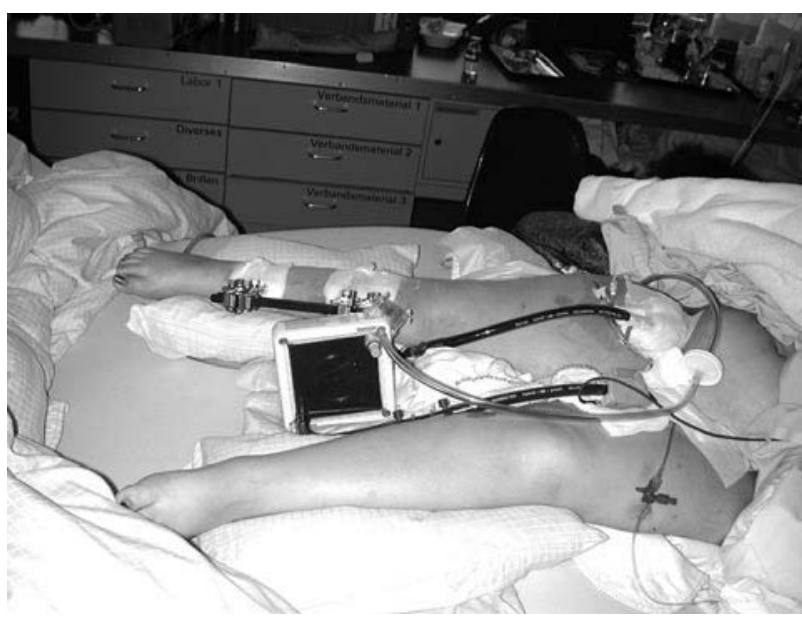

FIGURE This extracorporeal, pumpless lung assist device consists of an arterial and a venous cannula and the membrane oxygenator. The driving force is the arteriovenous pressure gradient of the patient's blood. Before insertion of the cannulae using Seldinger's technique, the internal diameters of the common femoral artery and vein have to be estimated by ultrasound. After insertion, the cannulae are clamped and connected to the prefilled tubing system containing the membrane oxygenator (Quadrox Spezial). As the total extracorporeal length (tip-to-tip) does not exceed $120 \mathrm{~cm}$, no heat exchanger is needed. An $\mathrm{O}_{2}$ supply line is connected to the inflow site of the membrane oxygenator with an $\mathrm{O}_{2}$ flow of 4 to $12 \mathrm{~L} \cdot \mathrm{min}^{-1}$. A continuous heparin infusion is connected to the arterial cannula to keep the activated clotting time at a level of 130 to $150 \mathrm{sec}$. A bidirectional ultrasound sensor is placed at the outflow line to determine the extra corporeal flow.

blood gas analysis showed a critical $\mathrm{PaO}_{2}$ of $60 \mathrm{mmHg}$ $\left(\mathrm{FIO}_{2} \mathrm{l} .0\right)$, a $\mathrm{PaCO}_{2}$ of $145 \mathrm{mmHg}$, and all conventional therapeutic efforts were exhausted; we decided to use a new lung assist device (NovaLung ${ }^{\mathrm{TM}}$ ) as a last attempt to save the patient (Figure). The Table presents the course of blood gas analyses and the respiratory parameters before and after the introduction of this device.

We inserted two 13-French cannulae into the femoral artery and vein, and connected them to the prefilled membrane oxygenator (Quadrox Spezial, Jostra Inc., Hirrlingen, Germany). After the extracorporeal circulation was instituted, the passive flow measured in the venous part of the system was 1.2 $\mathrm{L} \cdot \mathrm{min}^{-1}$ and the patient's blood pressure and heart rate remained unchanged. Oxygen saturation measured by pulse oximetry and $\mathrm{PaO}_{2}$ did not change. 
TABLE Respiratory parameters

\begin{tabular}{llllll}
\hline & Before PECLA & Day 2 PECLA & Day 5 PECLA & Day 8 PECLA & Day 10 PECLA \\
\hline $\mathrm{Vt}_{\mathrm{e}}(\mathrm{mL})$ & 160 & 225 & 250 & 300 & 320 \\
$\mathrm{MV}_{\mathrm{e}}\left(\mathrm{L} \cdot \mathrm{min}^{-1}\right)$ & 6.7 & 0.9 & 1.0 & 7.5 & 8.0 \\
$\mathrm{RR}_{\text {mech }}$ & 42 & 4 & 4 & 25 & 25 \\
$\mathrm{PaO}_{2}(\mathrm{mmHg}) / \mathrm{FIO}_{2}$ & 61 & 164 & 134 & 188 & 352 \\
$\mathrm{PaCO}_{2}(\mathrm{mmHg})$ & 145 & 56 & 56 & 50 & 55 \\
$\mathrm{pH}$ & 7.08 & 7.38 & 7.42 & 7.47 & 7.41 \\
\hline
\end{tabular}

PECLA = pumpless extracorporeal lung assist; $\mathrm{Vt}_{\mathrm{e}}=$ expiratory tidal volume; $\mathrm{MV}_{\mathrm{e}}=$ expiratory minute volume; $\mathrm{RR}_{\text {mech }}=$ mechanical respiratory rate.

We then started $\mathrm{O}_{2}$ flow at $6 \mathrm{~L} \cdot \mathrm{min}^{-1}$. At this point, arterial blood gas analyses were taken every five to ten minutes to adjust for the reduction in arterial $\mathrm{PaCO}_{2}$. Heparin was applied continuously to achieve and maintain an activated clotting time of 120 to $150 \mathrm{sec}$. The next step was the most critical. We tried to establish "apneic oxygenation" by reducing tidal volume and respiratory rate progressively. It required approximately six hours to reach stable conditions, and during this time $\mathrm{O}_{2}$ saturation decreased multiple times to values below $85 \%$. As we were not able to reach apneic oxygenation, we finally set the respiratory rate at 4 breaths. $\mathrm{min}^{-1}$; conventional biphasic positive airway pressures were 22 and $26 \mathrm{~cm} \mathrm{H}_{2} \mathrm{O}$ with an $\mathrm{FIO}_{2}$ of 1.0 and nitric oxide was applied at 8 ppm. Gas exchange gradually improved (Table), and hemodynamic parameters, diuresis, and temperature $\left(37^{\circ} \mathrm{C}\right)$ remained stable.

We did not change the ventilator settings over the course of the next five days, with the exception that $\mathrm{FIO}_{2}$ was carefully reduced to 0.7 , and the patient was gradually weaned off the nitric oxide. The sedation level was then reduced, spontaneous respiration gradually resumed, the patient awakened. On day eight following insertion of the lung assist device, the expiratory pressure level was reduced step by step to $14 \mathrm{~cm} \mathrm{H}_{2} \mathrm{O}$ with a mechanical respiratory rate of 25 breaths. $\mathrm{min}^{-1}$. On day ten, $\mathrm{FIO}_{2}$ was 0.4 , expiratory pressure level was decreased to $12 \mathrm{~cm} \mathrm{H}_{2} \mathrm{O}$, inspiratory pressure level was unchanged at $26 \mathrm{cmH}_{2} \mathrm{O}$ and mechanical respiratory rate was 25 breaths $\mathrm{min}^{-1}$. Blood flow through the NovaLung ${ }^{\mathrm{TM}}$ device was always between 0.9 and $1.2 \mathrm{~L} \cdot \mathrm{min}^{-1}$. We next stopped the $\mathrm{O}_{2}$ supply to the membrane oxygenator and, as there was no change in arterial $\mathrm{PaCO}_{2}$, a surgeon removed the cannulae and sutured the insertion sites of the vessels. The following weeks were complicated by several episodes of sepsis; but 104 days after admission our patient was transferred to a peripheral hos- pital, and ten weeks later she returned home without any further sequelae.

\section{Discussion}

Our case describes a young girl suffering from severe post-traumatic ARDS. Conventional and new therapeutic strategies were not effective, resulting in very high arterial $\mathrm{PaCO}_{2}$ levels with corresponding respiratory acidosis and low, but not yet life-threatening $\mathrm{PO}_{2}$ levels. Additionally, pleural leakage of air complicated mechanical ventilation. When $\mathrm{PaCO}_{2}$ intermittently rose to levels as high as $145 \mathrm{mmHg}$ and oxygenation deteriorated further, we decided to apply an extracorporeal gas exchange device. Because our university hospital does not provide pump-driven ECMO and the patient was not in a transferable state, the NovaLung ${ }^{\mathrm{TM}}$ device was the only available option.

This technique is attractive because of its simplicity and independence from machines. It is based on a low resistance lung assist device designed for pulsatile blood flow with tight diffusion membranes and a protein matrix coating. The gas exchange surface amounts to $1.3 \mathrm{~m}^{2}$. Blood-flow resistance across the membranes is reduced to an arteriovenous pressure gradient of approximately $15 \mathrm{mmHg}$ between inflow and outflow of the system, with pressure gradient being cannulae dependent but providing a trans device blood flow of up to $4 \mathrm{~L} \cdot \mathrm{min}^{-1} \cdot{ }^{10}$ The rationale for using such a device was not primarily to improve oxygenation, but more to minimize ventilator-associated lung injury, and to ameliorate and eliminate the inflammatory process that is enhanced by mechanical ventilation. With this method, complete removal of $\mathrm{CO}_{2}$ is possible within minutes by increasing $\mathrm{O}_{2}$ flow, but the drop in $\mathrm{CO}_{2}$ should be guided by the change in $\mathrm{pH} . \mathrm{PaO}_{2}$ values did not change after extracorporeal circulation was initiated, and an $\mathrm{O}_{2}$ flow of $6 \mathrm{~L} \cdot \mathrm{min}^{-1}$ was applied, but fell dramatically when we tried to incorporate apneic ventilation. 
There might be several reasons for the observed decrease in $\mathrm{PaO}_{2}$. First, a blood flow of $1 \mathrm{~L} \cdot \mathrm{min}^{-1}$ through the membrane oxygenator is quite low. This equals about $25 \%$ of the patient's cardiac output. The membrane oxygenator of the NovaLung ${ }^{\mathrm{TM}}$ device is based on the Quadrox ${ }^{\mathrm{TM}}$ heparin coated hollow fibre technology. Its low resistance produces a pressure gradient of only 10 to $15 \mathrm{mmHg}$ between inflow and outflow, providing a transmembrane oxygenator flow of up to $4 \mathrm{~L} \cdot \mathrm{min}^{-1}$, depending on the diameters of the cannulae. Since we were treating a young teenager with a femoral artery diameter of only $5 \mathrm{~mm}$, we had to insert a small 13-French cannula, resulting in a correspondingly low blood flow. Secondly, it is more difficult to oxygenate arterial blood than to use unsaturated venous blood, as is done in venovenous ECMO systems. Thirdly, the decrease of oxygen pressure in the blood was most prominent after we stopped ventilation completely, which caused the concentration of the simultaneously applied nitric oxide to increase and probably resulted in a further ventilation-perfusion mismatch. Once the increase was noted, it was resolved by providing minimal ventilation with a respiratory rate of 4 breaths $\mathrm{min}^{-1}$, with inspiratory and expiratory pressures of 26 and $22 \mathrm{~cm} \mathrm{H}_{2} \mathrm{O}$, respectively. After resolution, the concentrations of nitric oxide and arterial $\mathrm{PaO}_{2}$ remained stable. During the entire critical phase, the patient was ventilated in the biphasic positive airway pressure and assisted spontaneous breathing mode of an Evita 4 respirator (Draeger, Lübeck, Germany). This mode consists of pressure-controlled ventilation with tube compensation that allows spontaneous breaths during the entire mechanical cycle. The spontaneous efforts of the patient are pressure supported with tube compensation during the mechanical expiration phase.

Since the pulmonary parameters stabilized, we did not change the mechanical ventilatory settings for the next five days. Our intent was to allow the lungs to recover without the stress of repeated mechanical distension by the respirator. During this period, we only reduced $\mathrm{FIO}_{2}$ to 0.7 , based upon the $\mathrm{PaO}_{2}$ values, and the patient was weaned off nitric oxide. Because there is little experience on the best method to wean a patient from such a lung assist device, we had to define one. After five uneventful days of apneic ventilation, we reduced sedation and our patient began to spontaneously breathe with a respiratory rate of 25 breaths $\mathrm{min}^{-1}$. During the course of the next five days, we reduced the expiratory level of the bi-level positive airway pressure ventilation step-by-step to 14 $\mathrm{cm} \mathrm{H}_{2} \mathrm{O}$. The mechanical respiratory rate was adapted to the patient's initial spontaneous respiratory rate of 25 breaths $\mathrm{min}^{-1}$. Thus, tidal volumes were carefully augmented. Finally, on the tenth day of using the membrane oxygenator, a bi-level positive airway pressure modus was set at an $\mathrm{FIO}_{2}$ of 0.4 , inspiratory pressure level of $26 \mathrm{~cm} \mathrm{H}_{2} \mathrm{O}$, expiratory pressure level of $12 \mathrm{~cm} \mathrm{H}_{2} \mathrm{O}$, and a mechanical respiratory rate of 25 breaths. $\mathrm{min}^{-1}$, which resulted in tidal volumes of 350 to $400 \mathrm{~mL}$ and a minute volume of 8 to $9 \mathrm{~L} \cdot \mathrm{min}^{-1}$. After cessation of the external $\mathrm{O}_{2}$ supply to the membrane oxygenator, arterial blood gases remained stable over several hours. At this time, we decided to remove the NovaLung ${ }^{\mathrm{TM}}$.

In conclusion, arteriovenous pumpless extracorporeal lung assist is a reasonable complementary therapeutic option in the treatment of severe ARDS. Insertion can be done by an intensivist and, after an initial intensive monitoring phase, the NovaLung is a simple device to operate. Adverse events were not observed. Routine application in critically ill patients with ARDS appears possible, but future studies will be needed to demonstrate this, as well as to determine the indications that are optimal for its use.

\section{Acknowledgements}

The authors thank Klaus Weichelt for his support and the allocation of the transportable laboratory devices. In addition, the authors express their gratitude to Joan Etlinger for her assistance in preparing the manuscript.

\section{References}

1 The Acute Respiratory Distress Syndrome Network. Ventilation with lower tidal volumes as compared with traditional tidal volumes for acute lung injury and the acute respiratory distress syndrome. N Engl J Med 2000; 342: 1301-8.

2 Pulmonary Artery Catheter Consensus Conference Participants. Pulmonary artery catheter consensus conference: consensus statement. Crit Care Med 1997; 25: 910-25.

3 Amato MB, Barbas CS, Medeiros DM, et al. Effect of a protective-ventilation strategy on mortality in the acute respiratory distress syndrome. N Engl J Med 1998; 338: 347-54.

4 Putensen C, Mutz NJ, Putensen-Himmer G, Zinserling $J$. Spontaneous breathing during ventilatory support improves ventilation-perfusion distributions in patients with acute respiratory distress syndrome. Am J Respir Crit Care Med 1999; 159: 1241-8.

5 Gattinoni L, Tognoni G, Pesenti A, et al. Effect of prone positioning on the survival of patients with acute respiratory failure. N Engl J Med 2001; 345: 568-73.

6 Lundin S, Mang H, Smithies M, Stenqvist O, Frostell C. 
Inhalation of nitric oxide in acute lung injury: results of a European multicentre study. The European Study Group of Inhaled Nitric Oxide. Intensive Care Med 1999; 25: 911-9.

7 Gadek JE, DeMichele SJ, Karlstad MD, et al. Effect of enteral feeding with eicosapentaenoic acid, gammalinolenic acid, and antioxidants in patients with acute respiratory distress syndrome. Enteral Nutrition in ARDS Study Group. Crit Care Med 1999; 27: 140920.

8 Michaels AJ, Schriener RJ, Kolla S, et al. Extracorporeal life support in pulmonary failure after trauma. J

Trauma 1999; 46: 638-45.

9 David $M$, Heinrichs $W$. High-frequency oscillatory ventilation and an interventional lung assist device to treat hypoxaemia and hypercapnia. Br J Anaesth 2004; 93 : 582-6.

10 Liebold A, Reng CM, Philipp A, Pfeifer M, Birnbaum $D E$. Pumpless extracorporeal lung assist - experience with the first 20 cases. Eur J Cardiothorac Surg 2000; 17: 608-13. 